361 CORRELATION BETWEEN THE LEVELS OF BIOMARKERS P1NP, BAFF AND SCD40L SERUM WITH SKIN FIBROSIS BASED ON MODIFIED RODNAN'S SKIN SCORE IN SYSTEMIC SCLEROSIS

S Dewi ${ }^{*}$, A Alfarish, S Salim, V Halim, R Gunadi Wachjudi, L Hamijoyo. Universitas Padjadjaran, Internal medicine, Bandung, Indonesia

10.1136/lupus-2017-000215.361

Background and aims Systemic Sclerosis (SSc) is a chronic progressive autoimmune disease. Assessment of skin fibrosis based on modified Rodnan's skin score (mRSS) are important to determining clinical response and prognosis. Several biomarkers may potential to check skin fibrosis in SSc patients, such as B-cell Activating Factor (BAFF), Pro-collagen Type-1 Terminal Pro-peptide (P1NP), and sCD40L which believed playing role in fibrosis cascade. The aim of study is to evaluate the correlation levels of BAFF, P1NP and sCD40L serum with mRSS in SSc.

Methods This is a cross-sectional study enrolled SSc patients in Rheumatology clinic Hasan Sadikin Hospital Bandung-Indonesia, from Nov 2015 to July 2016. All subjects performed mRSS measurement and blood tests. Data analysed by RankSpearman correlation.

Results There are 42 subjects, mean age $40+10$ years old, 40 (95.2\%) are female, $24(57.1 \%)$ are limited type SSc and 18 $(42.9 \%)$ are diffuse type SSc. Thirty-nine (92.9\%) subjects treated with methotrexate, 29 (69\%) subjects with corticosteroid, and $4(9.5 \%)$ subjects with cyclophosphamide. The mean level of BAFF was $1090 \pm 386 \mathrm{pg} / \mathrm{mL}$, the mean level of sCD40L was $6858 \pm 2665 \mathrm{pg} / \mathrm{mL}$, and the mean level of P1NP was $51.5 \pm 25.7 \mathrm{ng} / \mathrm{ml}$. The median of mRSS was 17 (5-36). There are a significant correlation between $\mathrm{mRSS}$ and BAFF serum $(r=0.710 ; p=0.016)$, a significant correlation between mRSS and P1NP serum $(r=0.862, p=0.001)$, There are no significant correlation between mRSS and $\mathrm{sCD} 40 \mathrm{~L}$ serum $(\mathrm{r}=0.184 ; \mathrm{p}=0.318)$.

Conclusions Our study found a significant correlation between BAFF and P1NP serum with mRSS, and no significant correlation between sCD40L serum with mRSS in SSc patients.

\section{HEALTH-RELATED QUALITY OF LIFE (HRQOL), EMOTIONALITY THE DAY-TO-DAY PROBLEM SOLVING AND COPING IN LUPUS PATIENTS}

'A Domínguez-Gómez*, 'Ml Casado-Morales. 'Madrid Lupus Association, Psychology, Madrid, Spain; ${ }^{2}$ Complutense University Of Madrid, Psychology, Madrid, Spain

\subsection{6/lupus-2017-000215.362}

Background and aims This document presents the results of a study performed to assess the Health-related Quality of Life (HRQOL), emotionality and day-to-day problem solving and coping in lupus patients, compared to a control sample. This research is intended to analyse how symptoms affect to patients and what is the level of impairment associated to the disease perceived by them.

Methods The assessment was carried out by examining 35 lupus-diagnosed patients living in Madrid. Three questionnaires were used: SF-36 for measuring HRQOL, PANAS for quantifying positive and negative affect, ISAP for analysing problem solving and coping; additionally, a structured interview (LUPAM) to evaluate pain level and perceived level of impairment.
Results Main results found were that HRQOL level in lupus patients is lower than the average population, finding out differences also in the "past week Negative Affect" dimension. Nevertheless, statistically significant discrepancies between patient and control samples regarding to Problem Solving and Coping were not found.

Conclusions The study proves that patients perceive lupus and lupus-related disability in a worse manner depending on the disease phase, while there are some possible solutions to improve this perception such as the development of chronical pain programs.

\section{ANTI - TNF ALFA INDUCED LUPUS : A CASE REPORT}

A Fikn`*, P Faridin. Hasanuddin University, Internal Medicine, Makassar, Indonesia

\subsection{6/lupus-2017-000215.363}

Background and aims The use of protein based anti-TNF alfa therapies such as antibodies and soluble TNF alfa receptors is commonly associated with the induction of autoantibodies, whereas anti-TNF induced lupus (ATIL) is rare. ATIL can occur with any of the available TNF inhibitors, but the frequency and clinical characteristics of ATIL vary between different drugs.

Methods: Observational.

Results A 25 years old girl was diagnosed Rheumatoid Arthritis. Patient got MTX and Prednison 1 year ago. We add treatment with anti-TNF alfa (golimumab), after 2 weeks she got treatment, patient was suffer with hipertermia, dispnea, moon face,extremitals oedema and vasculitis. Laboratory result is anaemia, trombositopenia, LED was rise, C3 and C4 was decreased, hipoalbuminemia, ANA profile for any autoantibodies were positive. Then we diagnosed her anti-TNF Alfa drug induced Lupus (ATIL). We stop gift her anti-TNF Alfa and treated her with Prednison, MTX, and Furosemide Injection.

Conclusions Anti-TNF induced autoantibodies are common following therapy with all of the currently available anti-TNF therapies.However, the incidence of 'fullblown' ATIL is rare. Nevertheless, cerebral and renal involvement has been reported more frequently in ATIL compared with classical DIL. The incidence/prevalence of dsDNA antibodies and hypocomplementaemia is also greater in ATIL, whilst anti histone antibodies, the serological hallmark of classical DIL, are less commonly found. Due to the potentially serious complications of ATIL,screening for this prior to and during anti-TNF therapy might assume greater importance. If the diagnosis is suspected then anti-TNF therapy should be withdrawn unless symptoms are very mild.

\section{COMPARISON OF ADVERSE EFFECTS AND EFFICACY OF HIGH DOSE DEFLAZACORT VERSUS HIGH DOSE PREDNISOLONE IN SYSTEMIC LUPUS ERYTHEMATOSUS PATIENTS- A PROSPECTIVE COHORT STUDY}

${ }^{1} \mathrm{~A}$ Ganapati*, ${ }^{2} \mathrm{~T}$ David, ${ }^{3} \mathrm{~L}$ Jeyaseelan, ${ }^{3} \mathrm{~V}$ Jeyaseelan, ${ }^{3} \mathrm{~B}$ Yadav, ${ }^{1} \mathrm{D}$ Danda. ${ }^{1}$ Christian Medical College - Vellore, Department of Rheumtalogy, Vellore, India; ${ }^{2}$ Christian Medical College - Vellore, Department of Internal Medicine, Vellore, India; ${ }^{3}$ Christian Medical College - Vellore, Department of Biostatistics, Vellore, India

\subsection{6/lupus-2017-000215.364}

Background and aims Deflazacort (DFZ), oxazoline prednisolone (PDN) derivative, has dose equivalence of 1.2:1 (mg) to 